\title{
Policing the Pirates: Digital Models for Music Distribution
}

David P. Boyd, (E-mail: d.boyd@neu.edu), Northeastern University

\begin{abstract}
According to the entertainment industry, the digital revolution is usurping its product and undermining its profit. Internet Service Providers have shown reluctance to interfere in the private domain of their users so at the behest of Hollywood, Congress in 1998 passed the Digital Millennium Copyright Act. Nonetheless, the Recording Industry Association of America alleges that rampant Net piracy has precipitated a five percent worldwide decline of music sales in both 2000 and 2001. The personal computer has become an expedient means of downloading songs from peer-to-peer file-sharing services or "burning” CD copies onto a blank disk. To ensure compliance with the Act, some record labels have embraced technology that distorts the error correction codes on illegally copied CDs. However, this copy control solution is beset with various problems, including consumer aversion and technical fallibility. After examining the dialectical tension between business cost and consumer choice, this paper proposes some other options.
\end{abstract}

\section{Introduction}

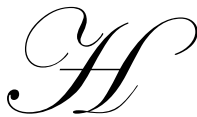

ollywood is under attack from Internet pirates. The music sector claims to be the hardest hit by the digital revolution. According to the Recording Industry Association of America (RIAA), modern-day Blackbeards are the prime reason for two consecutive years of five percent declines in worldwide music sales (Business Week, 2002). In dollar terms their incursion results in an annual loss of over $\$ 4$ billion (Biden, 2002, page 11). Due in large measure to piracy, 2002 sales of music CDs have fallen almost 13 percent while sales of singles have plunged 65 percent (Black, 2002c). Through peer-to-peer sites such as Morpheus, Kazaa, and Gnutella, computer users across the world engage in free file-swapping of copyrightprotected songs. Morpheus has been downloaded 60 million times in less than one year (Schonfeld, 2000). During one week in August 2002, the Kaaza homepage proclaimed that its software was downloaded nearly three million times (Black, 2002c). Consumers can access a global distribution system with ease and without expense. Intel co-founder Gordon Moore foresaw that computational power would double every 18 months. When one of Netscape's founders recently applied "Moore's Law" to digital entertainment, he predicted that by 2007 even the most rudimentary computer would contain the storage capacity to house 12,800 hours of music (Chmielewski, 2002). Today's music afficionado has realized a state of beatitude that transcends the external reality of economic necessity and legal compliance. The only requirement is the basic fee for Net access.

For the record labels there is no nirvana. Firmly ensconced in the popular culture, this digital medium can dance around the analogue establishment. Now that edge to edge interface has been vitalized through peerto-peer computing, the music industry finds itself in the unenviable position of resisting the technological innovations of a worldwide infrastructure. The recently introduced Berman bill would seem to allow copyright holders to invade and disrupt the personal files of those who illegally engage in P2P swapping (Wiltz, 2002, page A08). In pursuit of copyright crooks, record companies would be permitted to both "trespass" and "vandalize" (Salkever, 2002b, page 2). Yet as one popular rapper has opined: "Stopping the process of file sharing is like trying to control the rain" (Wilde, 2000, page 2).

Readers with comments or questions are encouraged to contact the author via email. 


\section{Business Calls on Government}

While the music industry's entreaties have been of little concern to the consumer, they have struck a more responsive chord in Washington. At the behest of Hollywood, Congress in 1998 passed the Digital Millennium Copyright Act (DMCA). Two years later this controversial legislation took full effect. According to the Act circumvention of copy protection systems for copyrighted work is a criminal offense. The outcry against such political interference was audible on both sides of the Atlantic. For example, an activist group in the United Kingdom called the Campaign for Digital Rights has vociferously lobbied against the DMCA, perhaps mindful that a precedent established in the United States could percolate to Europe. Such fears proved prophetic since last year the national governments of Europe approved the European Union Copyright Directive. If unmodified prior to its implementation at the end of 2002, the Directive will be even more restrictive than its American precursor.

Critics of the DMCA allege infringement of constitutional rights even as the labels decry consumer abrogation of commercial and artistic rights. The proscription against copying a duly purchased CD roils the public. Some argue that this restriction on backup copies violates the concept of fair use. Another aspect of the DMCA further incites freedom lovers. Not only is it illegal to engage in the act of cracking copyrighted technology, but it is also forbidden to offer technology that can do so. Even if initiated under the holy grail of research, some acts of reverse engineering are deemed criminal by the DMCA. Fearful of a RIAA lawsuit under the DMCA, a computer science professor from Princeton reneged on a speech about weaknesses in the recording industry's control technology for music protection. In another celebrated and politically charged case, a Russian programmer visited the United States to present a paper on cryptography. His paper explained how to create interoperable software for reading Adobe electronic books. He was subsequently arrested and charged with purveying knowledge of a circumvention device and decryption utility. After a furor ensued, he was ultimately allowed to return home. Nonetheless, the government succeeded in sending a powerful message to others who might be inclined to disseminate information on technological loopholes. As a result various academic and scientific bodies have elected to hold their technical conferences outside the United States (Gross, 2001). If academic discussion of circumvention techniques faces the growing possibility of legal stricture, then so surely will commercial distribution of circumvention devices. The classic corporate retort to copyright infringement has been that software per se is not illegal but rather the use to which it is put. Now liability is associated with abetting that use.

Additional digital rights management legislation is fermenting in Congress. Senate Foreign Relations Committee Chair Joseph Biden, a Democrat from Delaware, has introduced a bill that would expand counterfeit laws to include digital music. This legislation would make it illegal to replicate authentication measures on copyrighted materials. His Democratic colleague, Senator Commerce Committee Chair Fritz Hollings of South Carolina, has another bill pending that would directly and dramatically impact the consumer electronics and hardware industries. Responding to charges of OEM duplicity for providing features that facilitate proliferation, Hollings' Consumer Broadband and Digital Television Promotion Act (CBDTPA) would mandate copyprotection technology in all digital consumer devices. Moreover, the computer equipment would have to utilize security technologies certified and approved by the federal government. Under this bill the relevant players from the electronics, technology and security sectors have a year to agree on a security standard. In the event of an impasse, the Federal Communications Commission in consultation with the Register of Copyrights will try to broker a solution amenable to all parties. Hollings' proposal is more far reaching than the DMCA that preceded it. While the earlier legislation imposed penalties for violations of copyrighted intellectual property, the CBDTPA would compel consumers to purchase systems that purportedly prevented such infringement in the first place. The music industry is reveling while equipment manufacturers and consumer advocates are recoiling. Although many politicians agree with the high tech sector's view that industry should set technology standards, Congressional pressure is nonetheless mounting for such legislation. In fact, Representative Adam Schiff of California is introducing yet another bill that would provide specific protection of intellectual property that might otherwise be purloined over broadband channels. To some extent the agenda of all these bills is framed along partisan lines, with various Republicans opining that compulsory copyright protection is more of a Democratic issue. These Democrats will likely react to a Tinseltown temper tantrum. In the 2000 year election cycle, the 
entertainment media contributed $\$ 24.2$ million to Democrats and a more modest $\$ 13.3$ million to Republicans (McCullagh, 2002).

\section{Search for a Satisfying Solution}

If Digital Rights Management is going to be right, it must fairly align the interests of disparate parties. Record labels and artists clamor for protection of their royalty stream, but consumers inveigh against any legal encumbrance on products they have purchased. The argument against piracy appears credible. Unlike a record company, the pirate avoids the expense of searching for talent and then creating, producing and publicizing a recording. Nor does a pirate pay union fees, artists, back-up vocalists and musicians, publishing/songwriter royalties or taxes. Beyond the cost of purchasing a single commercial copy for use as a master, the pirate incurs only a nominal unit manufacturing cost. Conversely, it might be argued that copyright owners are egregiously extending the purview of intellectual property laws. The clarion of copyright becomes a means of aggrandizement as owners lay claim to all commercial value from every venue even where past practice and precedent have favored the individual (Lessig, 2001, page 11; Litman, 2001, page 14). Further complicating the interplay of buyer and seller, the government is flexing its regulatory might while equipment manufacturers herald the principle of self-governance. The cauldron surely does run over. The remainder of this paper offers a cost-benefit analysis of some alternative solutions.

\subsection{Avenue \# 1: control the network}

Seeking to secure a mainstay against further product encroachment and profit erosion, the labels have turned to the weaponry of technology. Through recourse to copy protection techniques, the industry aims to preserve its economic moat. Two such methods are "broken media" and digital watermarking. The first approach seeks to foil pirates by introducing a false value for the start time of the CD. The second approach is exemplified in Macrovision's SafeAudio technology. While SafeAudio is a type of digital watermarking, it is not the true watermarking that the company has developed for DVDs. The pure form lends itself to tracking, resulting in identification of the creator and thereby serving as a deterrent to copying DVDs. Rather than completely blocking $\mathrm{CD}$ replication, SafeAudio insinuates some digital distortion into a file, scrambling the data to feign the appearance of an uncorrectable error in the music bitstream. CD players and computers can interpolate the samples during playback, rendering the distortion inaudible. However, if consumers copy the song directly to a CD-ROM, their computer rendition will be punctuated by pops and clicks. Because this noise is audible, the pirated copy becomes devalued.

Though studios are holding a final decision in abeyance, they continue experimentation with such technologies, even slipping protected CDs into test markets. One industry concern is whether any of the touted solutions are indeed hack-proof. The "broken media" approach is highly vulnerable to the incursion of determined hackers. By resetting the start time to zero or simply running a digital output cord from a CD player to a computer, a clever consumer can circumvent copy controls. Rather than serving as a deterrent, technical barriers become a creative challenge for the young at heart who will use the Internet to showcase their virtuosity. As for purportedly secure digital watermarks, Macrovision's CEO avers that "under current technology, the advantage is to the hackers" (AudioFile, 2002, page 3). Felten's Princeton team apparently was able to crack all of the music industry's major audio copy-protection and watermarking schemes through reverse engineering. The team concluded that "no public watermark-based scheme intended to thwart copying will succeed ... If it is possible for a consumer to hear or see protected content, then it will be technically possible for the consumer to copy that content" (Elen, 2001, page 2). Echoing this sentiment, a California technology specialist on digital security conceded: "In the hands of Jane Hacker, no copy protection systems works" (Schneier, 2001, page 251). In fact, recognition of such limitations was a catalyst for the government's passage of the DMCA.

An even greater fear is how consumers will respond to such encryption even were it infallible. In addition to their perception that DRM legislation maligns rights, they would resist curtailment of their ability to customize music collections on their PCs. From a consumer perspective, an optimal format would be operative not only on a home computer but also on a PDA, cell phone or stereo player (Salkever, 2001). Moreover, 
consumer audiophiles claim to discern reduced quality in original copy-protected CDs. One early release in Germany reportedly had a four percent return rate. Although data are difficult to verify, a similar brouhaha surrounded the United Kingdom release of Natalie Imbruglia's White Lillies. To placate irate customers, Virgin Megastores replenished their stock with "uncorrupted" CDs. In view of such concerns, copy protection standards for music are likely to be more contentious than they were for video.

To the extent control is possible and palatable, partial lockdown is a more likely avenue. Various enterprise hardware firms are in pursuit of such a solution, including a consortium comprised of Hitachi, Intel, Matsushita, Sony and Toshiba. By embedding a chip in an entertainment device, these companies can prevent that digital equipment from communicating with another device. A "broadcast flag" contained in the device's outgoing digital signal could be read by software installed in a personal computer's media player. In this case audio flags would classify the content as "copy once," "copy always" or "copy never" (Cave, 2002, page 4).

When the call goes out for software, Microsoft also stands ready. Working with the copy protection companies, Microsoft has concocted a compromise through its Windows Media Audio digital format. The crux is to place two versions of an album on a single disc. One format is copy protected and thus not susceptible to modification. The second version on the $\mathrm{CD}$ is in a compressed computer audio format that is easily copied to a PC. However, Microsoft will include file restrictions that preclude online trading and unlimited replication. Consumers can thereby copy their retail purchase onto a PC, yet owners are protected from wanton proliferation. A Gartner spokesperson sees this approach as "a glimpse of the future" because its win-win mentality sets the stage for continued collaboration (Borland, 2001). Macrovision and its competitor SunnComm are both said to be near deployment. This middle ground, however, smacks of Microsoft monopoly for it would add to the company's arsenal a means of dislodging the prevalent MP3 format. With its $\$ 39$ billion cash horde, Microsoft's arms are forever extended and its motives may be considered rapacious. Nonetheless, as observed by digital music expert Aram Sinnreich, it could emerge as "a dark horse in online music" (Kontzer, 2001, page 1). The larger question is, of course, whether technology should enable or "enslave." By constraining the open architecture of the Internet, both Microsoft and Macrovision are buttressing the hegemony of the traditional labels. As Larry Lessig illustrates through political analogy, it seems anachronistic to allow communist control over Russia's future (Black, 2002a).

\subsection{Avenue \#2: free the network}

To find the sweet spot among labels, artists, and consumers, some observers advocate nontraditional business models. Instead of lobbying Congress, the music industry might leverage the digital rush with consumers. As distribution becomes commoditized," points of competitive distinction will increasingly revolve around related products and services (Black, 2002b). According to this view, distribution of original music should be complimentary while supplemental services carry a fee. Seizing upon such a strategy, the Grateful Dead has allowed concert fans to burn CDs by tapping into the rock band's engineering sound board. Since more revenues could be gleaned from concert attendance than album sales, the rock group recast the timehonored supplier-customer relationship (Wilder, 2000). Such upfront largesse has reaped dividends since the band's devotees spend $\$ 50$ million a year in ticket sales and $\$ 70$ million in general merchandise (Black, 2002b). Consonant with the concept of synergy, artists and their musical sponsors can increase their wealth by giving some of it away. Moreover, free online distribution might even augment retail sales. One survey (Sinnreich, 2001) suggests that file sharing can boost the sale of conventional CDs since peer-to-peer users also tend to be enthusiastic shoppers though a study commissioned by the RIAA reaches the opposite conclusion (Ordonez, 2002). In a somewhat analogous situation Massachusetts Institute of Technology President Charles Vest announced that hard copy sales of some campus textbooks increased when those books were first made freely available over the Internet.

Such revolutionary concepts of compensation for the music industry parallel a transformation occurring in the software arena. Just as Linux provides an open source for its software code, so might original songs be released without royalty or restriction. The Electronic Frontier Foundation (EEF), a civil liberties watchdog group founded in 1990, has proposed just such an Open Audio License. According to this scheme artists would 
receive an initial commission for their creative product. The Internet would then serve as a free channel for the reproduction and distribution of that intellectual creation. Thus the Web becomes the ultimate marketing medium for the industry itself rather than a haven for renegade mavens. Such facile and widespread dissemination would presumably enhance name recognition, resulting in customized benefits for the individual creator. The artist might, for example, be invited to compose additional songs or to perform private engagements. Payments to the music industry would continue in traditional form, as with retail CDs, although the EEF proposal would allow the artist to release one CD track as a promotional enticement. Moreover, Congress could establish a flat compulsory fee that Web sites pay to music publishers. Advocates such as Lessig urge that such fees be low and based on the current sampling methodology for radio distribution of music content (Black, 2002a).

\subsection{Avenue \#3: share the network}

Rather than steadfastly policing pirates or else simply accepting an ancillary role in digital distribution, the music industry might proactively partner. Music executives have castigated consumers for a lack of "mouse morality" and been slow to embrace an Internet model. The five major recording companies - Universal, Sony, EMI, Vivendi and BMG - have all launched download subscription services of their own. For a fee users can gain access to select portions of the music catalogues. Yet the success of these online efforts is modest because the labels offer too little and charge too much (Matthews, Peers and Wingfield, 2002). Consumers want their entertainment a la carte; they gravitate toward a few favorite songs and are loath to buy filler items. It behooves the music labels to establish sites where prospective purchasers can sample CDs on a track-by-track basis. The price point for single tracks is a sensitive concern. The labels clearly cannot recoup the sum they would have received from a full $\mathrm{CD}$.

If labels eschew the notion of their own music portals, they can sign licensing agreements with other Net distributors. According to the Gartner Group (McNealy, 2000), 35 percent of all consumer Internet access will occur at high speed by the end of 2002. Armed with a cable modem, twenty million surfers will be able to download a three-minute title in less than 30 seconds, and song quality will be commensurate with that of a CD. Targeting this audience, AOL Time Warner, Bertelsmann and EMI have launched a joint venture called MusicNet in conjunction with RealNetworks, a developer of multimedia software. As both a service and music content provider, MusicNet licenses its "private-label" platform to companies seeking to sell music subscription services under their own brands. The consortium has been fraught with problems, including partner friction and anti-trust concerns. Consumers protest against restrictions on how the product may be used. Songs are "streamed" to a computer but may not be downloaded to a hard disk or transferred to a portable player or CD burner. While MusicNet utilizes a set monthly fee, it is not the popular "all-you-can eat" model of flat rate billing. Only 100 songs may be downloaded, and they are disabled after 30 days. Showing some tractability in the face of price sensitivity, the other two large record companies - Sony and Universal - have backed a service called Pressplay. For $\$ 9.95$ a month it allows subscribers unlimited music downloads through Windows Media file format. Yet in one recent month the Pressplay homepage drew just 788,000 visitors and MusicNet an even more modest 154,000. By contrast Morpheus attracted 37 million visitors and Kaaza 25 million (Schonfeld, 2002).

The labels' nascent services at least signal that the music industry is crossing the digital divide. Moreover, the major record companies appear ready to cooperate with potential competitors. In July 2002, Listen.com's Rhapsody service announced that it had finalized licensing arrangements with all five labels. As the first independent online service to secure such a multi-faceted agreement, it can boast a content base of 175,000 songs. Through a comprehensive service like Rhapsody, even budding artists may find the shelf space to stock their music.

Rhapsody's scope and scale may finally position a fee-based service as a viable competitor to the freely accessed services - especially now that Morpheus and Kaaza are afflicted by everything from viral threats to decoy songs and popup ads. 


\section{Conclusion}

This paper has suggested some variant approaches to a quandary that is complex and seemingly confounding. Constituent actors will gravitate toward a format that resonates with their particular focus. The larger issues, though, should be framed in the context of reconciliation between business cost and consumer choice. Two emergent trends should serve as the panoply for any parameters that are established. First, power is visibly moving away from the traditional studio and toward the individual consumer. Second, online distribution is so potent a channel that the music industry can no longer prevent its use or preclude its utility. Ironically, with the demise of Napster, the music industry lost its best opportunity to control digital distribution through potential partnership. While the record companies need not jettison their analogue roots, they must recognize consumer preference. Otherwise digital buffs may end-run the industry itself. The general counsel for the Recording Industry Association of America recently conceded that the industry must give consumers "a satisfying music experience ... but without giving away the right to worldwide distribution" (Salkever, 2002a). It is unlikely that the network will be totally controlled any more than it will be totally free. Yet, as delineated in this paper's final model, the labels must devise ways of parlaying Internet infrastructure. As Aram Sinnreich, the analyst with Jupiter Research, cautioned: "Historically, when an industry is trying to move from one format to another, the successful way to do it is not to remove value from an old format but rather to add value to a new format" (Mariano, 2001). The entrenched powers of musical entertainment now find themselves embattled. Unless they move with foresight and flexibility, they may soon find themselves eclipsed.

\section{References}

1. $\quad$ AudioFile. 2002. Macrovision attempts copy protection. Techtv.com, March 21.

2. Biden, Joseph R. 2002. Theft of American intellectual property: Fighting crime abroad and at home. Washington, D.C.: Report from Senate Judiciary Subcommittee on Crime and Drugs.

3. Black, Jane. 2002a. Lawrence Lessig: The dinosaurs are taking over. Business Week Online, May 13.

$4 . \quad$ 2002b. The freebie road to digital riches. Business Week Online, May 13.

5 .

6. 2002c. The labels start turning up the volume. Business Week Online, August 12.

Borland, John. 2001. Compromise for CD copying is in the works. CNET News.com, September 28.

Cave, Damien. 2002. Chained melodies. Salon.com, March 13.

Chmielewski, Dawn C. 2002. Netscape executive: Entertainment industry's copy protection efforts will fail. San Jose Mercury News, April 10.

9. Elen, Richard. 2001. Hack-proof DVD-audio watermark cracked at Princeton - but under legal duress. Audiorevolution.com, April 27.

10. Gross, Robin D. 2001. Freedom of speech: Void where prohibited. Virtualrecordings.com, September.

11. Kontzer, Tony. 2001. He's got an ear for online music. Informationweek.com, January 1.

12. Lessig, Lawrence. 2001. The future of ideas: The fate of the commons in a connected world. New York: Random House.

13. Litman, Jessica. 2001. Digital copyright: Protecting intellectual property on the Internet. Amherst, NY: Prometheus Books.

14. Mariano, Gwendolyn. 2001. One million copy-protected CDs released. CNET News.com, August 8.

15. Mathews, Anna Wilde, Peers, Martin and Wingfield, Nick. 2002. The music industry is finally online, but few listen. Wall Street Journal, May 7.

16. McCullagh, Declan. 2002. Another punch for copy protection. Wired.com, March 28.

17. McNealy, P. J. 2000. Digital music distribution: Which model(s) will succeed? Stamford, CT: Gartner Group.

18. Ordonez, Jennifer. 2002. Sales of recorded music decline. Wall Street Journal, August 27.

19. Salkever, Alex. 2001. How to keep the digital music playing. Business Week Online, April 5.

20.

21.

22.

23.

24. 2002a. Taking the piracy fight too far. Business Week Online, July 9.

2002b. The RIAA: The piracy rate is growing. Business Week Online, May 13.

Schneier, Bruce. 2000. Secrets and lies: Digital security in a networked world. New York: John Wiley. Schonfeld, Erick. 2002. Goodbye Napster, hello Morpheus. ZDNet.com, March 18.

Wilder, Clinton. 2000. The Wilder side: Music industry's long, strange trip. Informationweek.com, August 21.

25. Wiltz, Teresa. 2002. Music debate heads to the hill. Washington Post, August 21, A08. 